\title{
A Joint Reading of Positional and Relational Goods
}

\author{
By Luca Fiorito and Massimiliano Vatiero ${ }^{1}$
}

\section{Introduction}

In a 1989 seminal paper published in Public Choice, Carole J. Uhlaner introduced the concept of relational goods within the rational choice theory ${ }^{2}$ :

These goods arise as a function of a relationship with others [...] Relational goods can only be enjoyed if shared with some others [...]. [Such goods] exist after appropriate joint actions have been taken by a person and nonarbitrary others [...] the others must either be specific individuals or drawn from some specific set. The identity of the "other" in relationship matters.(Uhlaner, 1989, p. 254, italics added)

These goods are therefore the outcome of the "joint" behaviour/consumption of a subset characterized by a group identity within a given population. Unlike private goods, relational goods are thus neither produced nor consumed by only one individual, otherwise the condition of joint consumption with others would not be given; relational goods also differ from public goods in that they are neither produced nor consumed by the totality of the population, which would preclude their identifying character.

Moreover, relational goods are characterized by an inverted rivalry or antirivalry in terms of consumption because of the fact that positive consumption by an individual increases along with sharing. This feature distinguishes them both from private goods (which are rival) and from public goods (which are non-rival).

Relational goods are not the only kind of goods characterized by joint consumption. As we will show in this essay, a further good - one closely related to relational goods - is characterized by joint consumption among individuals. The term "positional goods" (e.g. power, status, and prestige), introduced by Fred Hirsch in 1976, identifies those that are consumed for relative rather than absolute

\footnotetext{
1 The authors thank Luca Arnaudo, Stefano Bartolini, Antonio Nicita, Giuseppe Niglia, Ugo Pagano, an anonymous referee, and the participants in the annual conference of the Italian Society of Law and Economics (Turin, December 2011) for their useful suggestions. Thanks also to Caterina Mari for helping in the bibliographic search and Beatrice Giacometti for the translation. Any errors are, as always, the authors' responsibility.

${ }^{2}$ Besides Uhlaner (1989), please also refer to the following articles on the subject: Gui and Sugden (2005), Bruni and Porta (2007), Bruni and Zamagni (2007), and Bartolini (2010).
} 
value (see also Frank, 1985; McAdams, 1992; Schor, 1996; and Vatiero, 2009 and 2010). As stated in a well-known example by Hopkins and Kornienko (2004), the Jones family's choice of a new car will depend not only on whether it is big enough for their own needs, but also (if possible) on whether it is bigger than that of their neighbours. The issue of choice in consumption is not only a relation between producer and consumer, but also involves other consumers (and producers) in a manner similar to a status game (see Shubik, 1971).

As a result, both relational and positional goods are based upon an idea of joint consumption, though with opposite signs. In the case of a relational good, positive consumption by an individual is positively related to the consumption of that good by other individuals; in the case of a positional good, positive consumption by an individual increases if the negative consumption of that good by other individuals increases at the same time ${ }^{3}$ (see Pagano 1999, 2007, and 2010). In both cases, the economic agents no longer exclusively consider themselves; their well-being and consumption choices also depend on the consumption of other individuals.

Following the terminology of Leibenstein (1950), joint consumption of relational goods produces a bandwagon effect, whilst we can observe a snob effect in the case of positional goods. According to the concept of the bandwagon effect, demand for and consumption of a given good increase along with the consumption of that good by other individuals. The bandwagon effect represents "the desire of people to purchase a commodity in order to get into 'the swim of things'; in order to conform with people they wish to be associated with; in order to appear to be "one of the boys"' (Leibenstein, 1950, p. 189). Emulation, which is at the basis of the bandwagon effect, is a relation form itself that determines the relational outcome, i.e. a quasi-rent enjoyed by individuals sharing in consumption with the same sign of the object of emulation. This stimulates demand and therefore consumption by other individuals of the object of emulation, turning it into a relational good. In the case of positional goods, on the contrary, we witness Leibenstein's snob effect: "the desire of people to be exclusive; to be different; to dissociate themselves from the "common herd"" (Leibenstein, 1950, p. 189). Hence, the snob effect refers to situations in which an individual's demand for a good is inversely related to overall demand for said good. In other words, individuals prefer to set themselves apart rather than emulate others.

This note seeks to provide a joint examination of relational and positional goods, underlining the common aspect of sociality à la Uhlaner (1989). In particular, our thesis is that a close interconnection and dependence exist between

\footnotetext{
${ }^{3}$ Positional goods, like relational goods, are therefore neither private nor public goods (cf. Pagano 1999, 2007, and 2010).
} 
choices to consume relational and positional goods. Our explanation (though static) is therefore able to point out the theoretical connections between these two types of goods. It can also be supplemented by referring to the literature on cultural selection (see Boyd and Richerson, 2009 and 2010) and interdependence between competition and cooperation in economic evolution (see, among others, Bowles et al., 2010, § 2; and Bowles and Gintis, 2011, § 4-5). ${ }^{4}$

The rest of the note is structured as follows: section 2 presents a simple model in terms of coalitional games of the two types of goods; section 3 discusses the role of identity in both relational and positional goods. In section 4, we investigate the role of property rights for both types of goods. Section 5 is dedicated to our conclusions.

\section{Model}

Given a population $\Theta$ of $n$ individuals with $\Theta=\{1, \ldots, k, \ldots, n\}$, we use $S_{k}^{r} \subset \Theta$ to indicate a subset or coalition of $k$ individuals (from the whole $\Theta$ ) in which individuals choose to share, with the same sign, the consumption of a good (or initiate a similar action), represented by $x$. The superscript $r$ indicates a relational good as defined by Uhlaner (1989). We also identify with $v$ a function $R^{+} \rightarrow R$

that given the anti-rivalry character (which is a condition of superadditivity) of the consumption of the relational good, $v$ is an increasing function in $k$. If we indicate with $q_{k}^{r}>0$ the relational quasi-rent that develops among the individuals, the result is $q_{k}^{r}<q_{k+1}^{r}$ for each $k<n$. More generally, if the coalition composed of $k$ people is divided into two sub-coalitions, $S_{l}^{r}$ and $S_{m}^{r}$, a good is relational if

$$
S_{k}^{r}=\left(S_{l}^{r} \cup S_{m}^{r}\right)+q_{k}^{r}
$$

Where $S_{l}^{r} \cap S_{m}^{r}=0$ and $l+m=k$.

The coalitional game $\langle\Theta ; v\rangle$ of a relational good thus associates a real number $v(S)$ with each non-empty coalition $S$ of $\Theta$, such that

$$
v\left(S^{r}\right)=\left\{\begin{array}{ccc}
\sum_{i=1}^{k} \beta_{i} x_{i}-\gamma_{i} x_{i}+q_{k}^{r} & \text { if } & \underline{s}(x) \leq k \leq \bar{s}(x) \\
\sum_{i=1}^{k} \beta_{i} x_{i}-\gamma_{i} x_{i} & \text { if } & k<\underline{s}(x) \vee k>\bar{s}(x)
\end{array}\right.
$$

with $\beta$ and $\gamma$ respectively representing benefits and marginal costs with a positive consumption of $x$ for the individual $i$-th. If the good is purely relational, then $\beta=0$. In some definitions of relational goods, it is also assumed that they are free for individuals (see Nussbaum, 1986), meaning $\gamma=0$. We will assume more generally for function [2] that benefits are always greater than private costs, i.e. $\beta>\gamma$.

\footnotetext{
${ }^{4}$ Our thanks are due to the anonymous referee for this useful suggestion to extend the analysis.
} 
The values $\underline{s}(x)$ and $\bar{s}(x)$ respectively indicate the minimum and maximum number of individuals consuming $x$ who are able to produce a relational surplus. Given the identifying character of a relational good, if the individuals of a coalition are too few $(k<\underline{s}(x))$ or too numerous $(k>\bar{s}(x))$ with respect to the totality $\Theta$ in order to realise the relational quasi-rent, said good will determine only private benefits and costs (if any exist).

We can describe positional goods in a similar form to [2]. Uhlaner (1989, note 9, italics added) introduces a concept very similar to that of the positional good: "[i]n some circumstances persons seek to be unlike others. The analysis would carry through similarity if we assume relational goods in which the benefit is derived from dissimilarity". In other words, a positional good is based upon the relationship occurring among some agents, but emerges as a response to the desire to distinguish oneself (rather than conform, as with relational goods). In terms of consumption, we can distinguish the subset of agents $l$ with a positive consumption $x$ from the subset of agents $m$ with a negative consumption $(-x)$. In other words,

$$
S_{k}^{p}=\left(S_{l(x)}^{r} \cup S_{m(-x)}^{r}\right)+q_{k}^{p}
$$

where $S_{l(x)}^{r} \cap S_{m(-x)}^{r}=0$ and $l+m=k$.

Equation[3] describes the positional good - with the superscript $p$ precisely indicating a positional good - as the sum of two relational goods. That is, the relation established among the individuals $l$ who positively consume a good is positional to the relationship established among the individuals $m$ who exhibit a negative consumption of that good.

In [3], the quasi-rent $q_{k}^{p}$ can be both positive and negative. In the former case, the relation produces a surplus, meaning that the benefits for some (usually those who have a positive consumption) are greater than the losses for the others (those who have a negative consumption) even if the consumption has the opposite sign among the individuals. In the opposite situation $\left(q_{k}^{p}<0\right)$, the losses are greater than the relational benefits. The possibility that the positional relationship could produce losses on the whole rather than benefits distinguishes positional goods from relational goods; while the latter are always assumed to produce a surplus, this is not necessarily true for positional goods.

The characteristic function of the coalitional game $\langle\Theta ; v\rangle$ results in the following for positional goods:

$$
v\left(S^{p}\right)=\left\{\begin{array}{ccc}
v\left(s_{l(x)}^{r}\right)+v\left(s_{m(-x)}^{r}\right)+q_{k}^{p} & \text { se } \frac{l(x)}{m(-x)} \leq \overline{\bar{s}} \\
v\left(s_{l(x)}^{r}\right)+v\left(s_{m(-x)}^{r}\right) & \text { se } \frac{l(x)}{m(-x)}>\overline{\bar{S}}
\end{array}\right.
$$


Each of the two coalitions $s_{l(x)}^{r}$ and $s_{m(-x)}^{r}$ can develop a relational surplus on the inside, which is why we insert the superscript $r$. Unlike the characteristic function [2], in [4] we introduce the relational outcome of joint (but negative) consumption: $v\left(s_{m(-x)}^{r}\right)$. Moreover, as for relational goods, this results in a threshold limit value $\overline{\bar{S}}$ for positional goods, indicating the minimum exclusion level required to consume a positive quantity of a positional good. For example, the manifestation of an exercise of power (a typical positional good; see Pagano, 1999; Vatiero, 2009) requires, by definition, an exclusion: such an exercise implies that someone else is subject to that power, namely consumes a negative level of power, i.e. subjection (see Pagano, 1999).

Negotiation determines the solution of the game (e.g. core) and, except for problems due to coalition cyclicity, ${ }^{5}$ such a solution is Pareto-efficient.

\section{Identity in the relations}

There are goods with positional, relational, and private features. For example, consider the "consumption" of a motorbike: it determines private benefits, such as the driver's (and any passengers') transport; and private costs, such as the purchase price and maintenance costs. ${ }^{6}$ Moreover, it is a relational good because individuals who own some brand of motorbike and meet at rallies perceive themselves as belonging to a group with which they share a certain lifestyle (e.g. the so-called Guzzisti). The relational surplus depends on a joint and shared consumption from a plurality $k<\bar{s}$ of agents; apart from a limit superior, however, there is a limit inferior $\underline{s}$ below which a group identity is not perceived (and therefore not consumed). Finally, there is a positional component, assuming a status is positively consumed. This can be described as a (positional) juxtaposition between two coalitions. On one side we have the Guzzisti with their own relational outcome $v\left(s_{l(x)}^{r}\right)$, and on the other the coalition of those who do not consume this type of motorbike. This second coalition can form a relational outcome $\left(s_{m(-x)}^{r}\right)$ as well; think of Harley Davidson or bicycle enthusiasts, for

\footnotetext{
${ }^{5}$ To understand these problems, note that in [2], the superadditivity condition is not sufficient for the stability of the Pareto superior coalition. Since, as we assumed, $q_{k}^{r}>q_{k-1}^{r}$, the overall wellbeing will be at its maximum with $k=\bar{s}$ individuals. If it happens at the same time, however, that $q_{k=\bar{s}}^{r}<\frac{k}{k-1} q_{k-1}^{r}$, then the $(k-1)$ individuals will be incentivized to break the coalition $S_{k=\bar{s}}^{r}$; this is because the expulsion of (almost) one agent from the coalition increases the single payoffs of the agents inside the coalition. On the contrary, this will not occur if we assume that $q_{k=\bar{s}}^{r}>$ $\frac{k}{k-1} q_{k-1}^{r}$. Only in this case will the negotiation (assumed without negotiation costs) among the individuals ensure that efficiency is achieved. We can similarly demonstrate the same for the positional good described in the characteristic function [4].

${ }^{6}$ It can also illustrate a case of a public bad if we consider pollution.
} 
example. In both coalitions, the formation of the relational good will depend, as in the previous cases, on the limits $\bar{s}$ and $\underline{s}$. The positional surplus (or loss) $q_{k}^{p}$ will be determined by the preferences and subsequent utilities of the individuals included in the two coalitions.

Since positional goods can be described as a juxtaposition among relational goods, a motive for the formation of relational goods can therefore be their mere positional character. Indeed, an intrinsic feature of the relational good we have underlined is its identifying character:

Loving the Beatles with other people was more fun than loving them in solitude. Dedicated football fans gather before games and hold cookouts, drink beer, talk sports, hug each other, and catch up on personal news and gossip. Before a game, an NFL stadium parking lot radiates an air of intense bonding and sharing. Fans drive hundreds of miles to partake in these pregame gatherings, which are often a bigger attraction than the game itself. (Cowen 2000,p. 3, italics in the original text)

Excluding the private benefits that can be derived from the consumption of such goods, it is certain that the basis of consumption by these individuals is the relational good - sharing a preference for a music genre, supporting a team, etc. We must highlight, moreover, that these relational goods also have a positional nature: individuals who consume them confront individuals who consume "rival" relational goods (e.g. the fans of the Rolling Stones or the supporters of a rival team).

The identifying character can concern a small group, a community, a nation, or a wider population. Inside the reference group, individuals can develop a multiplicity of consumption sharing. Outside the reference group, this consumption can be seen as positional. ${ }^{7}$ The point lies in understanding if and when the positional motivations can increase at the expense of their relational counterparts. Veblen (1899) affirms that if the reference group is compact and its members are deeply familiar with one other, then leisure and consumption demonstrate wealth and social status without the necessity of showing them off. Meanwhile, conspicuous consumption becomes relevant in communities of strangers and/or "casual observers" (Veblen, 1899). Following Veblen's argument, the positional characteristics - flashy and conspicuous consumption increase as cohesion among individuals decreases; while this cohesion reduces the conspicuous and positional characteristics, it is also the basis of the formation of the relational goods. Greater (lower) social cohesion can thus increase (reduce)

\footnotetext{
7 A good example in this sense, presented by Ugo Pagano (1995), is nationalism. Another interesting case is reported by Bordandini and Cartocci (2009), who investigate a positional comparison between two groups (and the defence of one's own relational goods): Pakistani immigrants on the one hand and the indigenous members of communities in Argenta and Portomaggiore on the other hand.
} 
the reasons for the relational consumption of a good rather than those for positional consumption. Consequently, the more the "anonymous" population grows in density and the human relationships become more numerous (but less intimate and more complex), the more we observe an elaboration and selection process that boosts the development of new conspicuous methods. What emerges is the need to participate in large meetings with people who know nothing of our daily lives in places such as churches, theatres, parks, and so on. In such places, if it is true that relational goods will develop, it is also true that positional goods will do the same. Veblen (1899), for example, dwells at length upon places such as churches to highlight the ceremonial character of the functions and thus describe a certain degree of conspicuity in the participants.

\section{Property rights and the relational/positional treadmill}

Positional goods tend to be very exclusive; as Cowen writes $(2000$, p. 22, italics added):

[s]uccessful fan networks produce status for their fans as well as for the star. Exclusivist fans try to project images as non-conformists, hope to validate their self-esteem by being different, or simply wish to avoid the crowds associated with patronizing the truly famous. Fan networks do not usually try to include everybody, but instead exclude some individuals and portray them as outsiders.

Granting a limited run of a good or artificially reducing access to its consumption makes a good rare, and therefore distinct. In this sense, it can be useful to evaluate the introduction of property rights and the characteristic of exclusion that derives from it. Private property reinforces exclusion from consumption and increases, according to Veblen (1899), antagonistic distinction among individuals (and/or social classes). The consumption of positional goods is therefore more marked in the presence of private property. Conversely, their anti-rivalrous character causes relational goods to lose value if there are excluding mechanisms such as property rights ${ }^{8}$ because joint consumption becomes more viscous.

Borrowing a metaphor from an interesting book by Stefano Bartolini (2010), introductions of property rights on relational goods can be described as a (relational) treadmill. Such introductions aim to (artificially) make a relational good excludable for some individuals; doing so, however, reduces not only the well-being of those who are excluded, but also the benefit enjoyed by those consuming the good. Moreover, establishing property rights on such goods will most likely generate an exchange price - or at least an access price - that agents

${ }^{8}$ Examples for the introduction of property rights on relational goods are provided by Bartolini (2010). 
could pay by increasing their working hours and reducing their leisure time, which is precisely the time most suitable for consuming relational goods. Therefore, even if individuals can purchase relational goods, they do so at the expense of the consumption of these same goods due to their decreased leisure time (cf. Bartolini, 2010).

Meanwhile, there is also the positional treadmill. If more resources are spent in positional competition by all of the individuals involved, their own relative positions will not vary. Unlike Darwinists such as Veblen, who describes positional competition as a mere competition for rank superiority and basically one that does not satisfy material needs ${ }^{9}$, economists such as Cowen have criticised this statement and interpreted positional competition as a competition to obtain more plentiful means to fulfil one's own needs and achieve positive effects. Cowen (2000, p. 102) writes about the search for celebrity (a typical positional competition): "[t]he concentration of artistic achievements in particular points of space and time (Periclean Athens, the Florentine Renaissance, the Parisian Art World) reflects the fact that competition promotes rather than discourages star efforts" (p. 128). In greater detail (p. 119):

Rivalries often produce fame for both parties to the contest, rather than merely redistributing fame, as the zero-sum view would suggest. The duel of Mark McGwire and Sammy Sosa sparked great interest, as the two battled for single-season home run supremacy. Carl Lewis and Ben Johnson became the two most prominent track runners of the late twentieth century through their repeated confrontations. Magic Johnson and Larry Bird increased their renown through their basketball rivalry in the 1980s. Muhammad Ali owes part of his fame to having had the opportunity to fight Sonny Liston, Joe Frazier, and George Foreman, all worthy opponents

In this regard, it is plausible that the athletes named by Cowen enjoyed a certain celebrity merely because of engrossing (positional) "competition" with rivals of similar skill; but, as Cowen reminds us, celebrity is a rare good, meaning someone - by definition - must have suffered for the celebrity of these athletes. Therefore,

\footnotetext{
${ }^{9}$ On this matter, as Veblen reminds us reusing an idea from W. Bemis, when industrial efficiency reaches the point of offering more than mere subsistence, consumption becomes superfluous and motives referable to the exhibition of wealth and prosperity of the individuals involved find their place. Consumption is no more strictly interconnected with production through a convergence towards a balance of price and quantity, but related to the average consumption or with the consumption of other individuals within the community of the reference economic agent. According to Veblen, this conspicuous consumption is oriented towards the dissipation of resources due to four reasons: (i) unproductive consumption is generated, i.e. consumption is often concentrated on flashy and honorary, rather than useful goods; (ii) aversion is felt towards manual/productive work; (iii) the positional game can determine a winner and, if it does, the involved individuals have used resources without enjoying a benefit; and lastly, (iv) even if a winner should emerge, this class/group - with which an economic and politic power is often associated - will obstruct each step of social evolution with the aim of preserving itself. According to Veblen, the tendency towards emulation is probably the strongest and the most vigorous economic motive except for the instinct of self-preservation.
} 
in response to Cowen, we need to extend the reference population to include the "losers": for example, McGwire and Sosa both surpassed the single-season home run record held by Roger Maris. With this extension, we return once again to a zero-sum game perspective with winners and losers, which justifies the description of the positional competition as a treadmill - particularly with the introduction of excluding mechanisms such as property rights.

\section{Conclusions}

Relational goods and positional goods widen the traditional categories of economic goods. Both typologies are based on social interactions within a group, among groups, or, using Veblen's terminology, within a social class or among social classes. Relational goods imply an identifying character among individuals who are involved in their consumption. However, such a group characteristic has, like every other identity, a positional component vis-à-vis other groups. Analogously, except in a two-agent context, every positional good always has a relational component, as well.

This close interconnection between relational and positional goods is related to the sociality conditions on which both are based as economic goods. What emerges is a complex structure of interactions and relationships among individuals within a group or among groups that are able to produce an economic outcome; such an outcome would be ignored by standard analyses bound to the single categories of private goods versus public goods. 


\section{References}

Bartolini S. (2010), Manifesto per la felicità, Roma, Donzelli Editore.

Bordandini P. - Cartocci R. (2009), Cipolle a colazione. Identità locale e Immigrati a Portomaggiore e Argenta, Bologna, Il Mulino.

Boyd R. - Richerson P.J. (2009), Culture and the Evolution of Human Cooperation, Philosophical Transactions of the Royal Society (B), vol. 364, n. 1533, pp. 3281-3288.

Boyd R. - Richerson P.J. (2010), Transmission Coupling Mechanisms: Cultural Group Selection, Philosophical Transactions of the Royal Society (B), vol. 365, n. 1559, pp. 3787-3795.

Bowles S. - Edwards R. - Roosevelt F. (2010), Introduzione all'economica politica. Edizione italiana a cura di M. Vatiero, Milano, Springer-Verlag.

Bowles S. - Gintis H. (2011), A Cooperative Species-Human Reciprocity and its Evolution, Princeton and Oxford, Princeton University Press.

Bruni L. - Porta P. (2007), Handbook on the Economics of Happiness, Cheltenham, Elgar.

Bruni L. - Zamagni S. (2007), Civil Economy, Oxford, Peter Lang.

Cowen T. (2000), What Price Fame?, Cambridge (Mass.), Harvard University Press.

Frank R.H. (1985), Choosing the Right Pond: Human Behavior and the Quest for Status, New York, Oxford University Press.

Gui B. - Sudgen R. (2005), Economics and Social Interaction. Cambridge, Cambridge University Press.

Hirsch F. (1976), Social Limits to Growth, Cambridge (Mass.), Harvard University Press.

Hopkins E - Kornienko T. (2004), Running to Keep in the Same Place: Consumer Choice as a Game of Status, American Economic Review, vol. 94, n. 4, pp. 10851107.

Leibenstein H. (1950), Bandwagon, Snob, and Veblen Effects in the Theory of Consumers' Demand, Quarterly Journal of Economics, vol. 64, n. 2, pp. 183-207.

McAdams R.H. (1992), Relative Preferences, Yale Law Journal, vol. 102, n. 1, pp. 1-104.

Nussbaum M.C. (1986), The Fragility of Goodness: Luck and Ethics in Greek Tragedy and Philosophy, Cambridge, Cambridge University Press.

Pagano U. (1995), Can Economics Explain Nationalism?, in Breton A. et al. (a cura di), Nationalism and Rationality, Cambridge, Cambridge University Press, pp. 173-203. 
Pagano U. (1999), Is Power an Economic Good? Notes on Social Scarcity and the Economics of Positional Goods, in Bowles S. - Pagano U. - Franzini M. (a cura di), The Politics and the Economics of Power, Londra, Routledge, pp. 63-84.

Pagano U. (2007), Positional Goods and Asymmetric Development, in Yotopolus P. - Romano D. (a cura di), Asymmetries in Globalization, Londra, Routledge, pp. 28-47.

Pagano U. (2010), Posizioni giuridiche e complementarietà istituzionali, Studi e Note di Economia, vol. 15, n. 1, pp. 3-35.

Schor J. (1996), What's Wrong with Consumer Capitalism? The Joyless Economy after Twenty Years, Critical Review, vol. 10, pp. 495-508.

Shubik M. (1971), Games of Status, Behavioral Science, vol. 16, n. 2, pp. $117-$ 129.

Uhlaner C.J. (1989), Relational Goods and Participation: Incorporating Sociability into a Theory of Rational Action, Public Choice, vol. 62, n. 3, pp. 253-285.

Vatiero M. (2009), Understanding Power. A 'Law and Economics' Approach, Saarbrücken: VDM-Verlag Publisher.

Vatiero M. (2010), From W. N. Hohfeld to J.R. Commons, and Beyond? A Law and Economics Enquiry on Jural Relations, American Journal of Economics and Sociology, vol. 69, n. 2, pp. 840-66.

Veblen T. (1899), The Theory of the Leisure Class, Londra, Macmillan.

Summary: A Joint Reading of Positional and Relational Goods. (J.E.L. D11, K00)

Both relational and positional goods are based upon an idea of joint consumption - though with opposite signs. Indeed, in both cases, individuals' consumption choices take into account not only the individuals themselves, but others, as well. Given that relational goods provide a form of identity to their consumers, we show that a certain degree of positionality emerges within the consumption of relational goods. Analogously, except in a two-agent context, each positional good also has a relational component. What emerges is a complex structure of economic outcomes based on both relational and positional motives.

L'idea di consumo congiunto è alla base della definizione sia dei beni relazionali sia dei beni posizionali, sebbene nei due casi tale consumo abbia segno opposto. Infatti per entrambe le tipologie di bene economico le scelte di consumo sono other-regarded piuttosto che auto-interessate. Dato che il bene relazionale prevede un'identità tra i suoi consumatori, si mostra che un certo grado di posizionalità emerge anche nel consumo del bene relazionale. Parimenti, in contesti con più di due agenti, ogni bene posizionale ha anche una componente 
relazionale. Ne risulta una complessa struttura di outcome economici derivanti sia da ragioni relazionali sia da ragioni posizionali.

LUCA FIORITO is an associate professor of the history of economic thought at the University of Palermo, Italy. Email: luca.fiorito@unipa.it

MASSIMILIANO VATIERO is an assistant professor of law and economics and the Brenno Galli chair of law and economics at the Università della Svizzera italiana, Lugano, Switzerland. Email: vatierom@usi.ch 